Editors' Note: In "Long-term cerebral white and gray matter changes after preeclampsia," the authors found that preeclampsia was associated with chronic temporal lobe white matter changes and reduced cortical volume in young women; the changes were consistent with persistent inflammation. Dr. Culebras proposes that sleep apnea may be a contributing factor as pregnancy increases the risk of sleep apnea, which leads to inflammation and vascular morbidities, all of which may persist after pregnancy. Authors Siepmann et al. note that recent research shows an increased risk of stroke in patients with obstructive sleep apnea, possibly facilitated by intermittent hypoxia and vascular dysregulation. These mechanisms may relate to the authors' findings given the autonomic neurovascular dysfunction caused by preeclampsia. In "The autism 'epidemic': Ethical, legal, and social issues in a developmental spectrum disorder," the authors emphasized the importance of early screening and diagnosis of autism spectrum disorder (ASD). Machado et al. recommend assessing anatomic brain connectivity using the diffusion-weighted MRI technique and functional brain connectivity using EEG coherence calculations as part of the ASD diagnostic workup. Authors Graf et al. caution against this practice, citing that many studies fail to consistently implicate a specific neural network responsible for autism. The authors conclude that techniques such as those described by Machado et al. have a role in ASD research, but not yet in its routine clinical diagnosis.

-Megan Alcauskas, MD, and Steven Galetta, MD

\section{LETTER RE: LONG-TERM CEREBRAL WHITE AND GRAY MATTER CHANGES AFTER PREECLAMPSIA}

Antonio Culebras, Fayetteville, NY: The article by Siepmann et al. ${ }^{1}$ identified long-term cerebral white matter changes and reduced cortical volume, presumably of vascular origin, in young women after pregnancy complicated by preeclampsia. The authors invoked persistent inflammation as the putative agent. Sleep apnea may be a link among pregnancy, preeclampsia, and cerebrovascular disease.

During the third trimester of pregnancy, the growth of the fetus restricts sleep respiratory function, particularly in obese women. ${ }^{2}$ Ten percent of pregnant women have sleep apnea, ${ }^{2}$ a condition that raises blood pressure, increases the level of inflammation, and leads to preeclampsia. ${ }^{3}$ Sleep apnea may persist after pregnancy, sustaining the post-preeclampsia vascular risk.

In a study conducted in China, 29,961 women with sleep apnea had a 19\% higher risk of stroke and those in gestational age had the highest risk. ${ }^{4}$ In an editorial, ${ }^{5}$ I pointed out that pregnant women with sleep apnea develop a perfect storm of comorbid vascular events, featuring repeated hypoxia damaging the endothelium, release of placental proinflammatory factors, gestational hypertension, and preeclampsia. Sleep apnea remains underdiagnosed and obesity is expanding. A heightened level of awareness of sleep apnea is needed to take proactive preventive measures because sleep apnea is modifiable.

1. Siepmann T, Boardman H, Bilderbeck A, et al. Long-term cerebral white and gray matter changes after preeclampsia. Neurology 2017;88:1256-1264.

2. Pien GW, Fife D, Pack AI, Nkwuo JE, Schwab RJ. Changes in symptoms of sleep-disordered breathing during pregnancy. Sleep 2005;28:1299-1305.

3. Bourjeily G, Ankner G, Mohsenin V. Sleep-disordered breathing in pregnancy. Clin Chest Med 2011;32:175-189.

4. Chang CC, Chuang HC, Lin CL, et al. High incidence of stroke in young women with sleep apnea syndrome. Sleep Med 2014;15:410-414.

5. Culebras A. Sleep apnea and stroke in young women: the many faces of the disorder. Sleep Med 2014;15:377-378.

(C) 2017 American Academy of Neurology

\section{AUTHOR RESPONSE: LONG-TERM CEREBRAL WHITE AND GRAY MATTER CHANGES AFTER PREECLAMPSIA}

Timo Siepmann, Henry Boardman, Amy Bilderbeck, Ludovica Griffanti, Yvonne Kenworthy, Oxford, United Kingdom; Charlotte Zwager, Groningen, Netherlands; David McKean, Jane Francis, Stefan Neubauer, Grace Z. Yu, Adam J. Lewandowski, Yrsa Bergmann Sverrisdottir, Paul Leeson, Oxford, United Kingdom: We thank Dr. Culebras for the comment on our article. ${ }^{1}$ Sleep apnea might be among the pathophysiologic pathways linking preeclampsia with increased risk of cerebrovascular disease in previously preeclamptic women. In fact, research recently 
focused on the role of sleep apnea in the etiopathogenesis of cerebrovascular and cardiovascular disease and demonstrated an increased stroke risk in patients with obstructive sleep apnea (OSA) ${ }^{2,3}$ Intermittent hypoxia with consecutive vascular dysregulation has been identified as a possible mechanism whereby OSA increases risk of stroke. This might be relevant to previously preeclamptic mothers in whom autonomic neurovascular dysfunction, inter alia mediated by functional changes to the sympathetic nervous system, was also demonstrated. ${ }^{4}$ It remains to be answered whether this similarity among pathologies indeed points to a causative link between preeclampsia and cerebrovascular disease.

1. Siepmann $\mathrm{T}$, Boardman $\mathrm{H}$, Bilderbeck $\mathrm{A}$, et al. Long-term cerebral white and gray matter changes after preeclampsia. Neurology 2017;88:1256-1264.

2. Beaudin AE, Waltz X, Hanly PJ, Poulin MJ. Impact of obstructive sleep apnoea and intermittent hypoxia on cardiovascular and cerebrovascular regulation. Exp Physiol 2017;102:743-763.

3. Cho ER, Kim H, Seo HS, et al. Obstructive sleep apnea as a risk factor for silent cerebral infarction. J Sleep Res 2013; 22:452-458.

4. Stennett AK, Khalil RA. Neurovascular mechanisms of hypertension in pregnancy. Curr Neurovasc Res 2006;3: $131-148$

(C) 2017 American Academy of Neurology

LETTER RE: THE AUTISM “EPIDEMIC": ETHICAL, LEGAL, AND SOCIAL ISSUES IN A DEVELOPMENTAL SPECTRUM DISORDER

Calixto Machado, Mario Estevez, Rafael Rodriguez, Havana, Cuba; Gerry Leisman, Zichron Ya'acov, Haifa, Israel: Graf et al. ${ }^{1}$ wrote an interesting review on autism spectrum disorder (ASD), emphasizing the term "autism epidemic," supported by an editorial. ${ }^{2}$ Among other factors, increasing ASD diagnoses can be attributed to broader diagnostic criteria and the recognition of ASD existence differentiated from other neurodevelopmental diseases. ${ }^{2-4}$ One important issue, defended by the authors, is early screening and diagnosis with emphasis on the evolving practice of genetic testing for ASD.

Brain connectivity assessment, both anatomic and functional, is fundamental to diagnose and follow-up with intervention in ASD. ${ }^{3-5}$ Many studies assess either anatomic or functional measures, but literature regarding the correlation between both types of connectivity in autism is lacking. We studied children with autism, determining the relationship between anatomic and functional connectivity, with consideration of short-range and long-range brain networks. ${ }^{4}$ Anatomic measures were assessed by the diffusion-weighted MRI technique and functional measures by EEG coherence calculation. We found correlations among anatomic and functional connectivity, and concluded that an impaired audiovisual interaction in the right brain hemisphere might be the cause. ${ }^{4}$ The study of brain connectivity should be a tool to assess ASD in present and future research. ${ }^{3,4}$

1. Graf WD, Miller G, Epstein LG, Rapin I. The autism "epidemic": ethical, legal, and social issues in a developmental spectrum disorder. Neurology 2017;88:1371-1380.

2. Jeste SS, Schor NF. Autism today: have we put the cart before the horse? Neurology 2017;88:1303-1304.

3. Machado C, Estevez M, Leisman G, et al. QEEG spectral and coherence assessment of autistic children in three different experimental conditions. J Autism Dev Disord 2015; 45:406-424

4. Machado C, Rodriguez R, Estevez M, et al. Anatomic and functional connectivity relationship in autistic children during three different experimental conditions. Brain Connect 2015;5:487-496.

5. Chen S, Xing Y, Kang J. Latent and abnormal functional connectivity circuits in autism spectrum disorder Front Neurosci 2017;11:125.

C 2017 American Academy of Neurology

AUTHOR RESPONSE: THE AUTISM "EPIDEMIC": ETHICAL, LEGAL, AND SOCIAL ISSUES IN A DEVELOPMENTAL SPECTRUM DISORDER William D. Graf, Farmington; Geoffrey Miller, New Haven, CT; Leon G. Epstein, Chicago; Isabelle Rapin, New York: We thank Machado et al. for the comments on our review, ${ }^{1}$ and for the observations of abnormal anatomic and functional connectivity using diffusion-weighted MRI (DW-MRI). Innumerable studies have compared patients with autism spectrum disorders (ASD) and nonaffected controls at rest or while performing particular tasks, most often in small selected subject samples. For example, studies linked autism with the retino-collicular magnocellular visual pathways that project via the pulvinar to the amygdala, occipital V1, and multiple other areas, including the dorsal occipitoparietal/midtemporal streams, which participate with the frontal eye fields in processing spatial attention, moving targets, and dynamic facial expression (with inputs from the amygdala and other limbic pathways). ${ }^{2}$ However, no results consistently demonstrated specific neural networks that are uniquely pathognomonic of autism in the brain despite the fact that broad networks were linked with deficient social cognition in autism. ${ }^{3}$ Complex behaviors, like ASD, do not have a single endophenotype linked to one discrete neocortical location. ${ }^{4}$ The critical need for more research in autism should be balanced by caution about generalizing interpretations of neuroimaging findings that suggest the dysregulation of specific neural pathways. At present, DW-MRI and similar techniques, such as diffusion compartment imaging, are 
considered beneficial for research but not for routine clinical diagnostics.

1. Graf WD, Miller G, Epstein LG, Rapin I. The autism "epidemic": ethical, legal, and social issues in a developmental spectrum disorder. Neurology 2017;88:1371-1380.

2. Bernstein M, Yovel G. Two neural pathways of face processing: a critical evaluation of current models. Neurosci Biobehav Rev 2015;55:536-546.
3. Patriquin MA, DeRamus T, Libero LE, Laird A, Kana RK. Neuroanatomical and neurofunctional markers of social cognition in autism spectrum disorder. Hum Brain Mapp 2016;37:3957-3978.

4. Karmiloff-Smith A. Development itself is the key to understanding developmental disorders. Trends Cogn Sci 1998;2:389-398.

(C) 2017 American Academy of Neurology

\section{RETRACTION}

Mystery Case: $C S F-1 R$ mutation is a cause of intracranial cerebral calcifications, cysts, and leukoencephalopathy The authors retract the article "Mystery Case: CSF-1R mutation is a cause of intracranial cerebral calcifications, cysts, and leukoencephalopathy" by X. Ayrignac et al., which appeared in the Resident \& Fellow Section in volume 86, page e262, because 4 of the figures were previously published in another journal (European Neurology 2012;67:151-153). ${ }^{2}$ The earlier article was not cited and there were 3 common authors (Magnin, Berger, and Labauge) on the papers. In addition to the duplicate publication, 1 image attributed to the index case in this article was attributed to his mother in the earlier article and 3 images attributed to his mother in this article were attributed to the index case in the earlier article. When asked for an explanation, the corresponding author, X. Ayrignac, replied that he was unaware of the earlier paper, but agreed to represent all authors in retracting the paper. Coauthors Lumbroso, Mouzat, and Carra responded that they agreed with the retraction and were also unaware of the earlier publication and thus had no explanation for the mix-up of the figures or duplication publication. Coauthor Magnin, one of the overlapping authors, agreed with the retraction and stated that he did not know how the mix-up of the figures occurred and that he missed catching it at the manuscript review. Coauthor Labauge (an overlapping author) also agreed to the retraction and stated to the corresponding author that when he submitted the earlier paper, he did not realize the figures were incorrectly attributed and did not remember the first paper when he revised the Ayrignac et al. paper. Coauthor Berger (an overlapping author) was not available for a written reply, but the corresponding author stated that this author had verbally agreed to the retraction. None of the authors could explain the mix-up of the figures or the duplicate publication.

The corresponding author, Ayrignac, admits that this publication is a duplicate publication and thus should not have been published even with the identification of a mutation in the CSF1R gene. With regard to the mix-up of the figures, Ayrignac believes there was a mistake in the previous paper and that the images published in Neurology were correctly attributed to the index case and his mother.

\section{REFERENCES}

1. Ayrignac X, Mouzat K, Magnin E, et al. Mystery Case: CSF-1R mutation is a cause of intracranial cerebral calcifications, cysts, and leukoencephalopathy. Neurology 2016;87:e262-e263.

2. Labauge P, Berger E, Magnin E, Rumbach L, Mine M, Renard D. A new form of leukoencephalopathy with calcifications and cysts with nonrecessive inheritance and absence of gadolinium enhancement. Eur Neurol 2012;67: $151-153$. 


\title{
Neurology
}

Mystery Case: $C S F-1 R$ mutation is a cause of intracranial cerebral calcifications, cysts, and leukoencephalopathy

Neurology 2017;89;1311 Published Online before print September 1, 2017

DOI 10.1212/WNL.0000000000004439

This information is current as of September 1, 2017

\author{
Updated Information \& \\ Services \\ including high resolution figures, can be found at: \\ http://n.neurology.org/content/89/12/1311.full \\ References \\ This article cites 2 articles, 1 of which you can access for free at: \\ http://n.neurology.org/content/89/12/1311.full\#ref-list-1 \\ Permissions \& Licensing \\ Information about reproducing this article in parts (figures,tables) or in \\ its entirety can be found online at: \\ http://www.neurology.org/about/about_the_journal\#permissions \\ Reprints \\ Information about ordering reprints can be found online: \\ http://n.neurology.org/subscribers/advertise
}

Neurology ${ }^{\circledR}$ is the official journal of the American Academy of Neurology. Published continuously since 1951, it is now a weekly with 48 issues per year. Copyright (O 2017 American Academy of Neurology. All rights reserved. Print ISSN: 0028-3878. Online ISSN: 1526-632X.

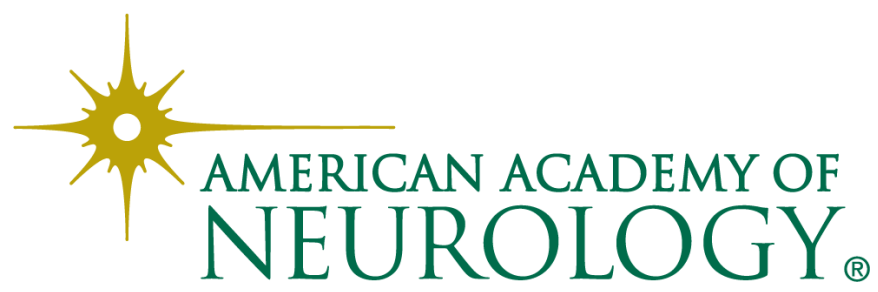

